\title{
Unease mounts over Japan's reform plan
}

[TокYо] Japanese scientists are increasingly concerned about a government plan to turn 14 basic research institutes attached to the Ministry of Education, Science, Sports and Culture (Monbusho) into semiautonomous 'agencies' with greater administrative independence.

The National Research Institutes for Joint University Use - which include the High Energy Acclerator Research Organization, the National Institute of Genetics (NIG) and the Institute of Space and Astronautical Sciences (ISAS) - are the latest target of the government's planned administrative reforms (see Nature 398, 5; 1999).

These are stand-alone entities with their own research staff, facilities and research agendas, but they are also used by university researchers, and some institute staff have affiliated positions at universities.

The plan, based on the UK 'Next Steps' initiative, seeks to improve administration by restructuring government ministries and agencies. It would create semi-autonomous bodies with separate management systems. Each institute would have its performance evaluated by an external assessment body every 3 to 5 years.

The plan initially included research institutes attached to science-related ministries, such as the National Institute of Radiological Sciences (see Nature 395, 211; 1998). But the government has recently made a proposal to turn institutes for joint university use into semi-autonomous institutions as well.
The government hopes to reduce the number of civil servants by 25 per cent within the next decade by giving agency status to government-run organizations. But critics argue that the government's aim is ambiguous, as they have announced that most of the agencies' staff will remain as civil servants.

Junichi Tomizawa, former director of NIG, says he is afraid that the restructuring will be used "as a scapegoat to cover up a possible failure to reduce the number of civil servants at other organizations".

Although many researchers support the plan's basic principles, such as giving the institutes greater flexibility in funding, they are opposed to its emphasis on performancerelated targets, which they say are inappropriate for basic research laboratories.

According to policy documents released in January, agencies would have an accounting system like that of private companies, with performance targets related to costs. But the government has now revised these targets, so that financial performance would not dictate the priorities of the research institutes.

But researchers are still concerned that the targets the research institutes would have to meet have not been adequately specified by the government. "Although the emphasis on cost performance is not necessarily explicit in the policy outlines, we are worried that the plan has been made within the framework of the administrative reform plan, which is aimed at reducing government costs" says Yoshiki Hotta, director of NIG.
Hotta also suggests that the performance of research institutes should not be judged in periods of 3 to 5 years, given the long-term nature of basic research. "Excellent scientific contributions are not necessarily regarded as good during their initial stages," he says

Some researchers are calling for a separate agency plan for basic research institutes, so that appropriate targets and evaluation systems can be introduced.

Tomizawa says the needs of the institutes and the national universities should be handled jointly. He is worried that their close relationship would be jeopardized if the institutes fall under a different administrative system to that of universities.

The government would like to turn universities into agencies, but has had to abandon this in the face of strong opposition from the academic community (see Nature 395, 730; 1998). Akito Arima, the education minister and director-general of the Science and Technology Agency, has declared that such reforms would harm both education and research. The government says it will not make a final decision on how the reforms will affect the national universities until 2003.

Minoru Oda, former director of ISAS, warns the universities against complacency. "Some of the powerful imperial universities, such as Tokyo and Kyoto, have this sense of security that they will not be subjected to any radical changes, while others have simply given up, thinking there is no way out from this agency plan," he says. AsakoSaegusa

\section{Libraries offer incentive for web-based rivals to 'costly' journals}

[WASHINGTON] A coalition of university libraries is stepping up its battle to circumvent the high price of specialized scientific journals by offering $\$ 0.5$ million dollars to universities and professional societies to come up with web-based information resources at universities.

The Scholarly Publishing and Academic Resources Coalition (SPARC), an offshoot of the Association of Research Libraries (see Nature 393, 719; 1998 and Nature 397, 195; 1999), last year helped to launch several journals to compete with publications which the libraries consider too expensive.

The coalition, which has 162 members, will make awards totalling $\$ 500,000$ to developers of web-based venues for publishing research. The money was raised from the $\$ 5,000$ annual dues of SPARC members, including the libraries of the universities of Harvard, Princeton, Johns Hopkins and California, as well as Canadian, Danish, Australian and British universities.

The idea, says Rick Johnson, SPARC's executive director, is to get applicants to find "new ways of disseminating research that are really responsive to the needs of scientists" and are cheaper than journals.

The aim is to create electronic repositories where research can be posted, discussed and seen by scientists worldwide, without waiting for journal publication.

The best-known model of such a resource - the Los Alamos e-print archives - is a "macro" example of what SPARC hopes to fund, says Jim Neal, dean of university libraries at Johns Hopkins University and a member of the SPARC steering committee. But he says proposals may range in strategy and structure.

One application for the SPARC awards is likely to come from Columbia University, where an earth-sciences web resource is being developed. Columbia Earthscape, a web-based publication scheduled for launch this autumn, will publish papers in their formative stages, early versions of conference proceedings, data sets and a magazine on science policy.

"We're not just trying to mimic on-line something that's available in print," says Kate Wittenberg, editor-in-chief at Columbia University Press. "We are trying to figure out ways to make very innovative, cutting-edge materials available at a cost possible for libraries to afford."

One weakness is how to entice scientists to use such sites when they lack the prestige of peer-reviewed, print journals. This is why support for the proposals from scientific societies is vital, says Johnson. "The prestige that a society can breathe into a venture is going to be very important."

In July, SPARC will help to launch a third journal to compete with an established publication. Organic Letters, to be published by the American Chemical Society, will be available in both print and electronic forms for $\$ 2,300$. Its competitor, Tetrahedron Letters, published by Elsevier, costs $\$ 9,862$.

SPARC supports alternative journals by delivering its library members as customers. So far, it has helped to launch Evolutionary Ecology Research and PhysChemComm, an electronic journal.
Meredith Wadman 